\title{
OPERACIONES CREDITICIAS DEL BANCO CENTRAL
}

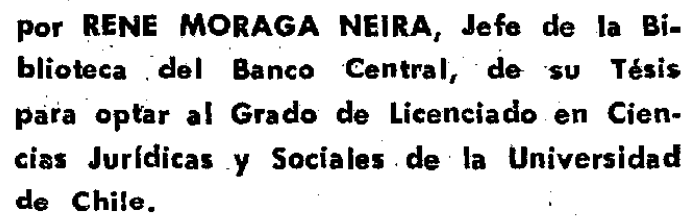

por RENE moraga Neira, Jefe de la Biblioteca del Banco Central, de su Tésis para optar al Grado de Licenciado en Ciencias Jurfdicas y Sociales de la Universidad de Chile.

\section{GENERALIDADES}

Entre los objetivos generales del Banco Central de Chile, existen tres que son de carácter netamente crediticio; es decir, persiguen la entrega de recursos monetarios presentes cuyo equivalente más los intereses deben ser restituídos en un futuro determinado. Estos objetivos son: a) Prestar recursos monetarios al Fisco e instituciones fiscales; b) Prestar recursos monetarios a las empresas bancarias, principalmente por medio del redescuento $y$ de préstamos especiales para ayudas de encaje; y c) Hacer préstamos al público en casos muy especiales.

Examinaremos a continuación los objetivos que señalamos con las letras a) y c), indicado en primer lugar, la disposición legal que faculta al Banco Central para realizar las operaciones crediticias relacionadas con estos objetivos.

\section{Préstamos al Fisco e institucione's fiscales}

Los préstamos del Banco Central al Fisco e instituciones fiscales se dividen en préstamos de carácter facultativo y préstamos de carácter obligatorio.

\section{Préstamos de carácter facultativo}

Los préstamos de carácter facultativo están señalados en el inciso 19 y letra a) del artículo 39 del D. F. L. 247 de 1960 y dispone que "el Banco Central de Chile, con arreglo a. las finalidades establecidas en el artículo $2^{\circ}$ del presente Decreto con Fuerza de Ley, y en ejercicio de su facultad emisora, podrá efectuar las siguientes operaciones: a) conceder créditos al Fisco, instituciones semifiscales, de administración autónoma y municipalidades, en las condiciones establecidas en leyes especiales".

El Fisco, que es el agente financiero del Estado para el cumplimiento de sus fines, requiere de grandes cantidades de recursos económicos. Estos los obtiene de la comunidad a través de impuestos y gravámenes o de inversiones, pero no siempre son suficientes $u$ oportunos; por lo cual necesita recurrir a instituciones financieras, tales como el Banco Central y el Banco del Estado, para que le adelanten los recursos monetarios en forma de préstamos especiales.

El carácter facultativo de los 
préstamos del Banco Central al Fisco e instituciones fiscales, emana de la misma disposición legal al establecer en el inciso $1^{\circ}$ del artículo 39 de su Ley Orgánica que el Banco Central "podrá" conceder créditos a las siguientes entidades:
a) Fisco ;
b) Instituciones semifiscales ;
c) Instituciones de administra- ción autónoma, y
d) Municipalidades.

La parte final del inciso $1^{\circ}$ de la letra a) del artículo 39, expresa que a estas entidades les puede conceder créditos en las condiciones que establezcan las leyes especiales, con lo cual prácticamente dejan de ser préstamos facultativos. En efecto, cuando se dicta una ley especial para que el Banco Central otorgue créditos a cualquiera de las mencionadas instituciones, el Banco se limita a concederlos en las condiciones que señale la ley, sin entrar a determinar si puede o no concederlos.

A continuación indicaremos las principales leyes que facultan al Banco Central para otorgar préstamos al Fisco, a instituciones semifiscales y de administración autónoma y a las muncipalidades.

\section{Leyes que autorizan la concesión de préstamos al Fisco}

Ley $\mathrm{N}^{0}$ 7.747. (Diario Oficial de 24 de Diciembre de 1943). Autoriza al Presidente de la República para emitir y colocar obligaciones fiscales con el objeto de disminuir el sobregiro de la Caja Fiscal y faculta al Banco Central para comprar bonos del Estado u otros valores de corto plazo. (Artículos 39, inc. 1.9 y 40 , letra c).
Ley $N^{\circ}$ 11.575. (Diario Oficial de 14 de Agosto de 1954). Faculta al Presidente de la República para contratar con la Caja Autónoma de Amortización de la Deuda Pública, préstamos en moneda extranjera con cargo a impuestos o a otros ingresos que el Fisco pueda percibir en oro o en moneda extranjera. Con este objeto la Caja podrá girar letras de cambio aceptadas por el Tesorero General de la República, las que podrán ser pagadas por la misma Caja o descontadas en el Banco Central de Chile, bancos comerciales del país o en bancos o instituciones financieras del exterior. (Artículo 53).

Se faculta además, al Presidente de la República para consolidar en una sola obligación, la deuda con el Banco Central de la Ley $\mathbf{N}^{0}$ 11.134. (Artículo 57).

Ley № 12.427. (Diario Oficial de 8 de Febrero de 1957). Autoriza al Presidente de la República para contratar uno o varios empréstitos internos en moneda nacional o externos en moneda extranjera y faculta al Banco Central y a otras instituciones para suscribir, tomar y conceder el todo o parte de los referidos empréstitos (artículos $1^{\circ}$ y $2^{\circ}$ ).

Ley $\mathrm{N}^{\circ}$ 12.967. (Diario Oficial de 2 de Septiembre de 1958). Autoriza al Presidente de la República para convertir y consolidar en un documento a largo plazo la obligación vigente con el Banco Central que ascendía a la suma de 6.000 millones de pesos con un interés de $1 \%$ anual y amortización acumulativa del 2\% anual. (Artículo $2 \%$ ).

Ley No 13.090. (Diario Oficial de 22 de Octubre de 1958). El Bánco Central podrá anticipar un trimestre del rendimiento de los impues- 
tos o contribuciones de las leyes $4.851,9.938,11.508$ y 12.017 , destinados a la construcción o reparación de caminos y puentes. (Artículo $6 .^{\circ}$ ).

Ley No 13.305. (Diario Oficial de 6 de Abril de 1959). Autoriza al Presidente de la República para refundir en una sola obligación, los préstamos en moneda extranjera que haya obtenido el Fisco del Banco Central por leyes anteriores hasta la suma de US \$ 87.372.333,26. (Artículo 91 ).

Ley No 13.904. (Diario Oficial de 13 de Enero de 1960). Autoriza al Banco Central para otorgar présta. mos al Fisco en moneda nacional o extranjera para realizar los aportes establecidos en el Convenio Constitutivo del Banco Interamericano de Desarrollo. (Artículo 3.\%, inciso 2..$^{\circ}$ ).

Ley $\mathrm{N}^{\circ}$ 14.171. (Diario Oficial de 26 de Octubre de 1960). Faculta al Banco Central para conceder préstamos en moneda extranjera que se hayan contratado en el exterior para el Fisco. (Artículo $7^{\circ}$, inciso $2^{\circ}$ ).

Ley $\mathrm{N}^{\circ}$ 14.171. (Diario Oficial de 26 de Octubre de 1960). Autoriza al Banco Central para realizar todas las operaciones necesarias a fin de aumentar la cuota de Chile en el Fondo Monetario Internacional y para suscribir a nombre del Gobierno de Chile, 233 nuevas acciones del Banco Internacional de Reconstrucción $\mathrm{y}$ Fomento $\mathrm{y}$ para estos fines conceder al Fisco préstamos en moneda nacional o extranjera. (Artículo 15).

Ley No 14.499. (Diario Oficial de 24 de Diciembre de 1960). Autoriza al Banco Central para otorgar préstamos al Fisco, en moneda nacional o extranjera y por las cantidades que sean necesarias para realizar los aportes y pagos que corresponden al Gobierno de Chile establecidos en el Convenio Constitutivo de la Asociación Internacional de Fomento (IDA). (Artículo único)

Ley No 14.949. (Diario Oficial de 11 de Octubre de 1962). Faculta al Presidente de la República para emitir pagarés a la orden y en dólares. (Artículo $2^{\circ}$ ).

El Banco Central podrá adquirir de los Bancos, a la par y en moneda. en que estén expresados los pagarés emitidos en conformidad a esta ley y a la $N^{\circ}$ i 14.171. (Artículos $6^{\circ}$, inciso $5^{\circ}$ ).

Ley $\mathrm{N}^{\circ}$ 15.120. (Diario Oficial de 3 de Enero de 1963). Autoriza al Presidente de la República para contraer obligaciones de acuerdo a la Ley 14.171, artículos $7,8,9$ y 10 que se refieren a la contratación de préstamos a corto y largo plazo y a la facultad concedida al Banco Central para otorgar préstamos en moneda extranjera al Fisco. (Artículo 52).

Ley № 15.453. (Diario Oficial de 28 de Diciembre de 1963). Autoriza al Banco Central para otorgar préstamos al Fisco en moneda nacional o extranjera para realizar los aportes y pagos de la cuota correspondiente a Chile del aumento de capital exigible del Banco Interamericano de Desarrollo y para enterar la contribución adicional del Gobierno al Fondo de Operaciones especiales de dicho Banco. (Artículo $2^{\circ}$ ).

Ley No 15.455. (Diario Oficial de 2 de Enero de 1964): Al igual que la Ley 15.120 es la que aprueba el Presupuesto de la Nación y establece las mismas facultades. (Artículo 41). 
Leyes que autorizan la concesión de préstamos a instituciones semifiscales

Ley No 9.869. (Diario Oficial de 5 de Febrero de 1951). Autoriza al Banco Central para conceder préstamos a la Caja de Previsión de Empleados Particulares hasta por 200 millones de pesos, al interés que el Banco cobra para las operaciones de redescuento a los bancos accionistas y por plazos no mayores de 90 días. (Actualmente no hay préstamos vigentes del Banco Central a esta Caja de Previsión ni a otros organismos previsionales de carácter semifiscal. Sólo queda un saldo del préstamo acordado a las Cajas de Previsión en virtud de la Ley 14.813).

Ley $\mathrm{N}^{\mathrm{o}}$ 14.813. (Diario Oficial de 29 de Diciembre de 1961). Autoriza a las instituciones de previsión para contratar con el Banco Central uno o más empréstitos para dar cumplimiento a esta ley que se refiere a los préstamos de las Cajas de Previsión a sus imponentes de las provincias de Atacama y Coquimbo. (Artículo $4^{\circ}$ ).

Ley No 16.251. (Diario Óficial de 4 de Mayo de 1965). Autoriza al Presidente de la República para dictar normas sobre otorgamiento de préstamos personales por la institución de Previsión Social, a los afiliados damnificados por el sismo del 28 de Marzo de 1965 y facultarlas para contratar créditos en el Banco Central de Chile, Banco del Estado y Bancos particulares.

Leyes quie autorizan la concesión de préstamos a instituciones de administración autónoma.

Ley $\mathrm{N}^{\circ}$ 14.171. (Diario Oficial de
26 de Octubre de 1960). Faculta al Banco Central para conceder préstamos en mơneda extranjera por intermedio de la Corporación de Fomento de la Producción, hasta un plazo de seis años. (Artículo 137).

Ley № 14.171. Faculta al Banco Central para conceder préstamos a plazos que no excedan de cinco años, a la Corporación de Fomento de la Producción, Corporación de la Reforma Agraria y Corporación de la Vivienda. (Artículo 139, que pasó a ser inciso $2^{\circ}$ de la letra c) del artículo 39 de la Ley Orgánica del Banco Centräl).

D.F.L. No 274. (Diario Oficial de 6 de Abril de 1960). Faculta al Banco Central para hacer préstamos a la Empresa de Comercio Agrícola, para que intervenga en la comercialización del cargo $\mathbf{u}$ otros productos agropecuarios o sus derivados. (Artículo 35).

Leyes que autorizan la concesión de préstamos a las Municipalidades.

No hay leyes vigentes que faculten al Banco Central para otorgar préstamos a las Municipalidades. El último crédito concedidó a las $\mathrm{Mu}$ nicipalidades se amortizó en el año 1955 y correspondía a un préstamo concedido por el Banco Central a la Municipalidad de Providencia, de acuerdo a lo dispuesto en la Ley № 8.787. (1).

Se ha estimado que al Banco Centràl no le corresponde financiar los gastos o las inversiones proyectadas por las Municipalidades. Cuando una Municipalidad necesita realizar un programa extraordinario de inversiones que no puede financiar con recursos o ingresos ordinarios,

(1) Diario Oficial de 5 de Julio de 1947 . 
se autoriza al Banco del Estado paia que contrate con la Municipalidad respectiva, uno o varios préstamos hasta un monto determinado en la ley, que para este efecto se dicta especialmente, a fin de que pueda efectuar las inversiones proyectadas.

\section{Préstamos de carácter obligatorio Fuente legal,}

Los préstarhós de carácter obliga. torio del Banco Central al Fisco es. tán : señalados en el inciso $2^{\circ}$ de la letra a) del artículo 39 del D.F.L. 247 de 1960, que establece que "no obstante el carácter facultativo de ias operaciones indicadas en el inciso anterior, el Banco deberá descontar letras de cambio giradas por la Caja Autónoma de Amortización de la Deuda Pública, a cargo del Tesorero General de la República, por el plazo y condiciones $y$ ' hasta por el monto señalado en la Ley $\mathrm{N}^{\circ} 7.200$ de 21 de Julio de 1942, con el objeto de regularizar los ingresos de la Caja Fiscal. Los documentos que se descuenten en virtud de esta disposición no podrán exceder, en ningún momento a un duodécimo del Presupuesto anual de la Nación; ni tampoco podrán exceder en un semestre del $66 \%$ del monto total de ese dúodécimo".

\section{Requisitos.}

De acuerdo con lo expresado en la Ley Orgánica del Banco Central en la disposición transcrita y en la Ley $\mathrm{N}^{\circ} 7.200$, modificada por la Ley N.9 11.575 (2), los requisitos que deben existir para que operen los préstamos obligatorios del Banco Central al Fisco, son los siguientes : a) Deben concederse mediante descuentos de letras de cambio;

b) Las letras de cambio deben ser giradas por la Caja Autónoma de Amortización de la Deuda Pública y aceptadas por el Tesorero General de la República;

c) Los documentos descontados no deben-exceder al monto corespondiente a un duodécimo del Presupuesto Anual de la Nación, ni tampoco exceder, en un semestre, del $66 \%$ del monto total de ese duodécimo;

d) El producto de los préstamos debe destinarse a regularizar los ingresos de la Caja Fiscal;

c) Los descuentos deben concederse a cuenta de impuestos por percibir; (3)

f) Lös préstamos deben cuncederse por un plazo máximo de seis meses y a un interés del 1\% anual; (3) y

g) Los préstamos deben estar cancelados al 31 de Diciembre de cada año (3).

Los préstamos obligatorios del Banco Central al Fisco mediante descuéntos de letras en las condiciones recién reseñadas fuerón utilizaros frecuentemente por el Gobierno hasta el año 1958. En 1959 el Fisco no recurrio al financiamiento del Banco Central mediante descuentos y en los años 1960 y 1961, solicitó en muy poeas ocasiones este tipo de préstamos.

En los años siguientes ha aumentado la cantidad solicitada como puede apreciarse en el cuadro esstadístico que se inserta más adelante. pero no en forma considerable, ya

(2) Diario Oficial de 14 de Agosto de 1954.

(3) Artículo 15 de la Ley N: 7.200, modificado por la Ley No 11.575. 
que el Fisco ha preferido utilizar los préstamos directos concedidos por el Banco Central de acuerdo a leyes especiales y además ha recurrido a los créditos externos en los cuales el Banco Central le adelanta, en mo- neda corriente, el valor del crédito acordado en el exterior, obligándose el Fisco a restituirlo al momento de recibir los préstamos en moneda extranjera.

\section{PREstamos DEL BANCO CENTRAL AL FISCO}

EN MONEDA CORRIENTE (En miles de $\mathrm{E}^{\text {? }}$ )
EN MONEDA EXTRANJERA (En miles de US\$)

\begin{tabular}{lccc|cccccc}
\hline Año & & Fisco & Inst. Públicas & Total & Año & & Fisco & Inst. Públicas & Total \\
& 1 & 2 & $1+2$ & & 1 & 2 & $1+2$ \\
\hline 1960 & 140 & 8.437 & 8.577 & 1960 & 191.383 & 6.000 & 197.383 \\
1961 & 813 & 37.878 & 38.691 & 1961 & 267.582 & -630 & 267.582 \\
1962 & 16.398 & 55.996 & 72.394 & 1962 & 367,168 & 630 & 367.798 \\
1963 & 56.270 & 61.202 & 117.472 & 1963 & 410.575 & 1.528 & 412.103 \\
1964 & 81,200 & 63.153 & 144.353 & 1964 & 455.826 & 13.608 & 469.434 \\
\hline
\end{tabular}

\section{Préstamos directos al público}

\section{Generalidades. -}

Hemos señalado que uno de los objetivos de un banco central es la de hacer préstamos al público en condiciones muy especiales. Sin embargo algunos autores estiman que el Banco Central como una institución reguladora del crédito $y$ a cargo de la política monetaria debiera quedar al margen de las operaciones con el público por corresponder a las demás empresas bancarias.

El Banco Central al desempeñar el papel de banco de los bancos necesita de la colaboración de las demás empresas bancarias para cumplir su función de tal, pero al realizar las operaciones con el público, propias de los bancos comerciales, estaría actuando como un competidor en ventajosas condiciones, en desmedro de la colaboración que necesita.
Nosotros creemos que el Banco Central no debe actuar como banco comercial propiamente tal, es decir, realizar toda clase de operaciones con el público, pero si que puede y debe operar con el público en forma restringida bajo circunstancia; extraordinarias para estar en condiciones de regular el crédito cuando se ha debilitado el mercado monetario. o para favorecer determinadas actividades necesarias para la economía nacional.

La Ley Orgánica del Banco Central señala dos operaciones por intermedio de las cuales interviene directamente con el público : el descuento de letras y los préstamo warrants. A estos últimos nos referiremos al estudiar los préstamos agrícolas del Banco Central. Existe una tercera operación directa del Banco Central con el público, señalada en la Ley 7.397. a la que también nö referiremos en este párrafo. 


\section{Descuentos de letras}

La letra e) del artículo 39 del D.F.L. 247 de 1960 señala que el Banco Central podrá. "descontar letras al público cuyo origen sea la producción agrícola, industrial o minera, o negocios destinados a facilitar la exportación o importación y la circulación o colocación de productos en los mercados: Los plazos de vencimiento de estas letras serán los contemplados en el número 3 , letra b) de este artículo"

"Las operaciones que' se autoricen en conformidad a lo dispuesto en esta letra, deberán llevar a lo menos dos firmas de primera clase".

"Serán aplicables a las operaciones de descuento con el público las prohibiciones señaladas en la letra b de este artículo".

De acuerdo con lo prescrito en esta disposición, para que opere el descuento de letras con el público deben existir los siguientes requisitos:

a) Debe tratarse de letras cuyo origen sea la producción agrícola, industrial o minera, o negocios destinados a facilitar la exportación o importación y la circulación o colocación de productós en los mercados ;

b) Las letras presentadas al descuento deberán llevar, a lo menos dos firmas de primera clase, entendiéndose por tales aquellas cuya responsabilidad cubra con exceso sús obligaciones directas y que las informaciones o antecedentes de que se disponga, acrediten el cumplimiento fiel y oportuno de sus compromisos ; $y$

c) Que los plazos que falten para el vencimiento de estas letras no ex- cedan de 90 días, o de 180 , cuando tengan su origen en la producción agrícola, o de un año, cuando el Directorio estime conveniente estimular calificados rubros de la producción nacional.

La referencia que la dispoosición legal recién transcrita hace a la letra b) del artículo 39 significa que al Banco Central en sus operaciones con el público se le prohibe descontar:

a) Los documentos cuyos origen importe inversiones permanentes ya sea en bienes raíces o muebles, salvo que el Directorio autorice, excepcionalmente y por razones fundadas, determinadas operaciones de esta naturaleza; y

b) Los documentos que tengan su origen en el servicio de óbligaciones, en fines de consumo on el financiamiento de negocios especulativos.

Estas limitaciones son las mismas que el legislador estableció para las operaciones de redescuento del Ban'co, Central con los bancos accionistas, lo que está demostrando la $\mathbf{r i}^{2}$ gurosidad $e_{\text {, }}$ igualdad de condiciones con que el Banco Central trata las operaciones de redescuento con los bancos y las operaciones con el público.

Esto lo interpretamos como la in. tención manifiesta de tratar de evitar el financiamiento al público y sólo conceder descuentos cuando se considere necesario y en casos muy calificados, con fines de regulación monetaria y crediticia de acuerdo a lo establecido en el artículo 40 de la Ley: Orgánica.

La mencionada disposición expresa que las operaciones de descuento de letras al público "sólo podrán efectuarse con fines de regulación 
monetaria o crediticia, Corresponderá al Directorio señálar los límites globales de estas operauones su oriantación económià̃ orndiciones. intereses, plazos y demás modalidades que estime convenientes, en acuerdo que requerirá el voto conforme de siete Directores".

Esta última disposición termina por reglamentar en detalla las operaciones de descuentós del Banco Central con el público, seüalando los dernás requisitos que se deberán cumplir en el Directorio para aprobar los acuerdos relativos a esta materia.

Uno de los últimón acuerdos del Directorio del Banćo Central que se refiere a los descuentos utin el público, es el aprobado en sesión № 2.011 de 3 de febrero de 1965. (4). Este acuerdo autorizó al Comité de Operaciones del Directorio para descontar letras correspondientes a liquidaciones o pagos a cuenta de próximas entregas de productos agricolas de la cosecha 1964-1965 También se autorizó para descontar letras a cuenta de liquidaciones o pagos dè productos agrícolas anteriores a la mencionada cosecha, siempre que se trate de arroz,cebada maíz, oleaginosas, lanas, remolachas, cuyos plazos de vencimiento no sean stiperiores a 180 días, o de trigo, a 210 días, o de leche, a 90 días.

Descuento de letrás a covENSA Y CAP.

Entre las operaciones de descuento que podríamos llamar habituales con el público, el Banco Central concede créditos a la industria salitrera y a la siderúrgica por intermedio de la Corporación de Ventas de Salitre y Yodo y la Compañía de Acero del Pacífico.

El acuerdo del Directorio del Banco Central $\mathrm{N}^{\circ} 2.002$ de 2 de dicienbre de 1964 amplía la línea de crédito concedido a COVENSA por acuerdos N.os 1:926 de 8 de mayo de $1963 ; 1.946$ de 9 de octubre de 1963 ; 1.982 de 22 de julio de $1964 ; 1.989$ de 9 de septiembre de 1964 y 1.993 de 7 de octubre de 1964 y dispone que el crédito operará mediante descuento de letras aceptadas por distribuidores o usuarios de salitre o yodo, a plazos que fluctúan entre 180 y 360 días y a un interés del $12 \%$ anual.

El acuerdo № 1.984 de 5 de agosto de 1964 , por su parte amplía el margen de crédito concedido a la CAP a que se refieren los acuerdos N.os 1.927 de 15 de mayo de 1963 y 1.948 de 23 de octubre de 1963 , y establece que la Compañía podrá utilizarlo indistintamente, tanto para el descuento de letras a cargo de industriales metalúrgicos, como para aquellos documentós aceptados por la misma CAP, no pudiendo sobrepasar el monto total de estas operaciones del margen de crédito fijado en là sesión $\mathrm{N}^{\mathbf{0}}$ 1:984. (E: 9:500.00).

\section{Préstamos especiales a cooperativas de consumo.}

Son los concedidos por el Banco Central a las cooperativas de consumo de acuerdo a lo establecido en la Ley No 7.397 (5).

A virtud de lo dispuesto en la mencionada ley, para que proceda el otorgamiento de estos préstamos, es

(4) Boletín Mensual del Banco Central de Chille, marzo de 1965, p. 318 .

(5) Diario Oficial de " 7 dé enero de 1943. 
necesario que existan los siguientes requilsitos :

a) Debe tratarse de cooperativas de cơnsumo que hubieren obtenfo personalidad juridica de dcuefo la Ley de Cooperativas (6);

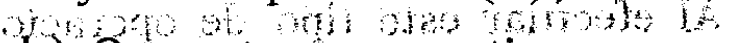

b) Que estas cooperativassposean un capital pagado, y reservas no in feriores a 3 mil eseudos m

c) Que tengan a 10 menos $5 \mathrm{mil}$ socios;

d) Que hayan funcionado a lo menos tres años consecutivos, contados desde la fecha del decreto que otorga la personalidad jurídica;

e) Que en los dos últimos años de funcionamiento, hayan repartido entre sus asociados, saldo a favor o excedente que equivalgan a un interés. no menor del $5 \%$ anual sobre los aportes de los socios; y

f) Que los préstamos sean autorizados por decreto supremo del Presidente de la República.

La Ley 7.397 establece además, las siguientes modalidades para la concesión de lós préstamos del Banco Central a las cooperativas de consumo:

a) El total de los préstamos otorgados por el Banco Central a cada cooperativa no podrá ser superior al monto del capital pagado y reservas de la cooperativa que solicita el prés tamo; y

b) Cáda préstamos se concederá hasta 180 días plazo, mediante pagarés y el Banco cobrará una tasa de interés igual a la que fije para los redescuentos a los bancos accionis tas.

Cón relación a estas operaciones podlemós décir que el Báné Centrá ha concedido ent thuy pocas ocasiones este tipo de crédito siguiendo su política" đe dbsteñếrse fasta donde sea posible, de otorgar financiamiento a particulares. Adetinas, desde 1960 hasta 1965, sólo se han dicțado tres decretos dèl Ministerio de Economia autorizando a otras tan tas cooperativas para solicitar préstamos al Banco Central (7).

Por la práctica seguida en este tipo de préstamos, debe entenderse que los decretos constituyen autorizaciones permanentes a las cooperativas individualizadas en los respectivos decretos, para solicitar, en cualquier momento al Banco Central, préstamos hásta por las sumas autorizadas. Sin embargo, debemos hacer notar que las sumas autoriza. das por los decretos no son obligatorias para el Banco Central ya que el Directorio en su Sésión No 1.839 de 26 de julio de 1961, limitó los préstamos hasta por la suma de 6 mil escudos para cada cooperativa, no debiendo sobrepasar el total de préstamos vigentes del Banco Central a estas instituciones, de $40 \mathrm{mil}$ escuidos. Asimismo dispuso en esta sesión que los préstamos a las cooperativas se efectuarían a un $6 \%$ de interés anual, aún cuando el interés que se aplica a los redescuentos de los bancos accionistas es superior. Es decir que la disposición de la Ley 7.397 que se refirió a la igualdad de ambos tipos de interés se habría in-

(6) Decreto RRA N: 20, que fijó el texto refundido actualizado y sistematizado del D.F.L. N: 326 de 1960. Diario Oficial de 5 de abril dé 1963.

(7) Decretos N.os 814 de 1961 y 380 y 1.505 de 1964. Diario. Oficial de 1:1 de julio de 1961;' 14 de mayo de 1964 y 26 de enero de 1965 respectivamente. 
terpretado como una facultad concedida al Banco Central para aplicar. cualquier tasa de interés. siempre que no sea' superior a la que cóbra para las operaciones de redescuento de los bancơs accionistás.

\section{PRESTAMOS AGRICOLAS}

\section{,}

\section{Generalidadés}

Varias de las operaciones que el Banco Central está facultádo para efectuar de acuerdo a su Ley Orgánica, se refieren al financiamiento directo o indirecto a la agricultura. Ya hemos examinado tres de estas operaciones al referirnos al redescuento del Banco Central a los bancos accionistas, al descuento de letras al público y a los préstamos especiales que concede a varias instituciones.

En efecto, la letra b) del artículo 39 , se refiere, entre otros aspectos, al redescuento a los bancos accionistas de letras cuyo origen sea la producción agrícola; el inciso $2^{\circ}$ de la misma disposición alude a los préstamos especiales a plazos que no excedan de cinco años concedidos por el Banco Central a la Corporación de la Reforma Agraria; y la letra e) del mismo artículo 39 se refiere a los descuentos al público de letras cuyo origen sea la producción agrícola.

Existen además dos tipos de préstamos agrícolas con características especiales. Uno de ellos está señalado en la misma Ley Orgánica en la letra f) del artículo 39, que reglamenta los llamados préstamos warrants y la otra, en una ley especial: el D.F.L. 274 de 1960, cuyo artículo
35 faculta al Bance Central para otorgar préstamos a la Empresa de Comercio Agrícola.

\section{Redescuento de letras de producción agricola a los banoos accionistas.}

Al efectuar este tipo de operaciones el Banco Central realiza un financiamiento indirecto a las actividades agrícolas ya que proporciona los recursos a las instituciones dis. tribuidoras del crédito destinado a la agricultura.

Para estos créditos el Banco ha establecido normas de carácter general relativas al monto y a las actividades que deben favorecerse. En algunas ocasiones ha señalado un rubro determinado de la agricultura que puede ser beneficiado con préstamos agrícolas de los bancos comerciales o del Banco del Estado. Un ejemplo lo constituye el acuerdo No 2.011 del Directorio del Banco Central. (8) Según éste acuerdo se faculta a la Gerencia General para redescontar a los bancos comerciales y al Banco del Estado letras que procedan de la liquidación de la cosecha de vinos del períado 1964-1965.

\section{Préstamos a la Corporación de Re forma Agraria.}

El Banco Central está facultado, de acuerdo con el inciso 2 ' letra b) del artículo 39 de su Ley Orgánica, para conceder préstamos de hasta cinco años plazo a la Corporación de Reforma Agraria, institución que reemplazó a la Caja de Colonización Agrícola por Ley $\mathrm{N}^{\circ} 15.020$ (9). Estos préstamos, al igual que los concedidos por intermedio del redes-

(8) Boletín Mensual del Banco de Chile, marzo de 1965, p. 318.

(9) Diario Oficial de 15 de noviembre de 1962. 
cuento de letras de producción a lós bancos accionistas, forman parte del financiamiento indirecto del Banco Central a las actividades agrícolas del país.

\section{Descuento de letras de producción agrícola al público.}

En los descuentos al público de letras cuyo origén sea la producción agrícola, el Banco Central, en la mayoría de los casos, realiza un financiamiento directo a la agricultura. Decimos en la mayoría de los casos, porque en algunas ocasiones efectúa operaciones de descuento a instituciones que a su vez van a distribuir el crédito recibido del Banco Centrál.

En el caso de operaciones de descuento de letras que provengan de las actividaes agrícolas, el Banco Central, a través de diversos acuerdos del Directorio y por instrucciories de las autoridades ejecutivas, ha señalado las normas precisas en cuanto a los siguientes rubros:

a) Personas o instituciones a cuyo cargo se deben, es decir, los aceptantes de las letras que pueden presentarse al descuento;

b) Tipo de las letras susceptibles de ser descontadas en el Banco Central, es decir, el origen agrícola de las letras;

c) Plazo de vencimiento de las letras; $\mathrm{y}$

d) Interés anual que cobra el Banco Central por las operaciones de deścuento a los agricultores.

De acuerdo con estas normas básicas, el Banco Central, actualmente concede los siguientes préstamos: a) Descuento de letras a cargo de industriales que sean usuarios o distribuidores de productos agropecuarios, cuyos plazos de vencimientos no sean superiores a 180 días y a

b) Descuento de letras a cargo de un interés del $17 \%$ anual (10). industriales molineros por anticipos para liquidación de contratos relativos a trigo, cuyos plazos de vencimiento no sean superiores a 210 días, aplicándoles un interés del $17 \%$ anual (10):

c) Descuento de letras a cooperativas agrícolas a cargo de industriales y giradas por el productor de trigo, cuyos plazos de vencimiento no sean superiores a 210 días, aplicándoles una tasa de interés correspondiente al $13 \%$ anual.

d) Descuento de letras a cooperativas agrícolas a cargo de industriales y giradas por el agricultor por productos agropecuarios especialmente señalados y cuyos vencimientos no excedan de 180 días y a un interés anual del 13\%. Los productos que se aceptan para estos descuentos son : arroz, cebada, maíz, oleaginosas, lanas, remolacha, leche y trigo. Los plazos máximos para la leche y el trigo son de excepción y se extienden hasta 90 y 210 días, respectivamente.

\section{Préstamos warrants}

Se establecen en el artículo 39, letra f) del D.F.L. 247 de 1960 al expresar que el Banco Central podrá "efectuar préstamos a plazo que no excedan de 180 días y con garantía de productos y destinados a atender lạ producción de carácter estacional, cuyo aprovechamiento y consumo requieren plazos adecuados".

(10) El Acuerdo NN 2.018 de 31 de marzo de 1965, subió el interés del 16 al $17 \%$. 
"Estos préstamós se otorgarán con arreglo a las disposiciones de la Ley de Almacenes Generales de De: pósitos!.

Los préstamos a que se refiere la dísposición transcrita se conocén con el nombre de préstàmos wärrants y al igual que las operaciones de des cuentos al público, "sớlo pédrán éfeé. tuarse con fines de regulación mó netaria o crediticia Correspondera al Directorio sefialar los límítes globales de estas operaciones, si orientación económica, condiciones, intereses, plazos y demás modalidades que estime convenientes en acuerdo que requerirá el vóto conforme de siete Directores"..

De acuerdo con el inciso final de la letra f) del artículo 39 de la Ley Orgánica del Banco Central, los préstamos warrants deben otorgarse con arreglo a la Ley de Almacenes Generàles de Depósitos. Está contenida en el Decreto $\mathrm{N}^{\mathrm{o}} 38$ de 4 de marzo de 1932 (11), que refunde las disposiciones de las leyes 3.896 y 5.069 .

Nos interesa examinar el artículo 27 que establece que "el Banco Centralde Chile', con endosos de vales de prenda, emitidos por los almacenes generales, podrá hacer présta mos hasta por 180 días, y descontar letras para cuyo vencimiento no falten más de 180 días, a la tasa de interés o descuento que fija para los bancos accionistas".

"El monto de cada préstamo no podrá ser superior al $70 \%$ del valor comercial del producto dado en prenda".

"En caso de descuento de letras con garantía de vales de prenda, el mónto de éstos pòdrá ser igual al valor comercial del producto dado én prendà".:

De acuerdo con el artículo 27 , se establecen dos tipos de préstamos warrants: préstamos mediante $\mathrm{el}$ simple endoso del vale de pronda préstamos mediante descuento de letras con endoso del vale de prenda. Los requisitos de ambos son los si guientes:

a) Deben estar garantizados por vales de prenda emitidos por los almacenes generales;

b) El plazo máximo de los présta mos no debe ser superior a los 180 . días y el plazo que falte para el vencimiento de las letras no debe ser superior a 180 días, cuando se trate de descuentos;

c) Se les debe aplicar el mismo intèrés que rige para las operaciones de descuento a los bancos accionistas ;

d) El monto de los préstamos no debe ser superior al $70 \%$ del valor comercial del producto dado en prenda, ni superior a éste, cuando se trate de descuentos.

Del contexto de la Ley de Almacenes Generales de Depósitos se desprende que los almanecenes de depósito son establecimientos comerciales autorizados legalmente para recibir y custodiar productos y mercaderías de cualquier naturaleza y otorgar por ellos títulos especiales llamados certificados de depósito y vale de prenda que tienen por objeto transferir el dominio y constituir garantía prendaría de los productos y mercaderías depositados.

De acuerdo con esto el Banco Cen-

(11) Diario Oficial de 4 de abril-de 1932. 
tral podría conceder prestamos y cescuentos con garantía de cualquier producto depositado en almacenes legalmente autorizados, pero los concede respecto de los productos agricolas solamente a virtud de lo establecido en su Ley Orgánica que expresa que debe tratarse de productos destinados a atender la producción de carácter estacional.

La importancia que el Banco Central otorga al financiamiento agricola a través de lós préstamos warrants se puede apreciar al considerar que dưrante el año 1964, del total de las colocaciones del Banco Central con el público, 78,6 millones de escudos, 11,8 millones de escudos corresponden a préstamos varrants, lo que representa alrededor de un $15 \%$.

\section{Préstamos a la Empresa de Comer- cio Agrícola.}

Respecto de la Empresa de, Comercio Agrícola, el Banco Central opera no sólo a través del descuento, sino que mediante préstamos con letras, pagarés y otros instrumentos de acuerdo a lo establecido en el artículo 35 del D.F.L. 274 de 1960 (12), al disponer que "el Banco Central de Chile podrá hacer préstamos a la Empresa de Comercio Agrícola, mediante letras, pagarés u otros instrumentos a fin de que intervenga en la comercialización del trígo u otros productos agropecuarios y sus derivados. Asimismo, el Banco Central podrá descontar a la Empresa las letras de cambio provenientes de operaciones sobre dichos productos".

En virtud de esta disposición el Banco Central ha concedido 'numerosos préstamos a la ECA y los últimos acuerdos que se relacionan con esta materia son los signados con los N.os 1.982 de 22 de julio de 1964 y 1.999 de 18 de noviembre del mismo año.

El acuerdo del Directorio del Banco Central de su Sesión $\mathrm{N}^{\circ} \mathbf{1 . 9 8 2}$, aprueba préstamos con letras concedidos a la ECA con un plazo de 90 días y a un interés del $3 \%$ destinados al financiamiento de una importación de trigo realizada de acuerdo al Quinto Convenio de Excedentes Agropecuarios de los Estados Unidos.

El acuerdo de la Sesión No 1.999 , aprueba préstamos con letras al plazo de hasta 180 días, con un interés del $3 \%$ anual para destinar los recursos a la apertura de un poder comprador nacional para el trigo de Ja cosecha 1964-i965.

\section{Limitaciones crediticias del Banco Central}

Generalidades:

En este capítulo relativo a las operaciones crediticias del Banco Central, hemos creído conveniente enunciar las limitaciones o prohibiciones contenidas en la Ley Orgánica. Ya hemos hecho referencia a ellas al tratar cada una de las operaciones en particular ,de manera que aquí las reseñamos y sistematizamos:

\section{Enunciado}

El Banco Central de Chile al realizar operaciones crediticias no podrá:

a) Redescontar letras o descontar pagarés $\mathbf{u}$ otros documentos a los bancos comerciales. cuando ellos sean el producto de inversiones per*

112) Crea la Empresa de Comercia Agrícola. Publicada en iel Diario Oficial de 6 de abril te 1960. 
manentes en bienes raíces o muebles, salvo que el Directorio autorice, excepcionalmente y por razones fundadas, determinadas operaciones de esta naturaleza; (Artículo 39, letra b) $\mathrm{N}^{\mathrm{o}} 1$, inciso $2^{\circ}$ ).

b) Redescontar o descontar a los bancos accionistas, letras pagarés u otros documentos cuyo origen sea el servicio de obligaciones, el consumo o negocios especulativos; (Artículo 39 , letra b) inciso $3^{\circ}$ ):

c) Ceder documentos de su cartera de colocaciones o de inversiones, a Ias empresas bancarias y demás instituciones de crédito, que a la fecha de la operación tengan obligaciones pendientes con el Banco Central; (Artículo 39, letra d) inciso $2^{\circ}$ ).

d) Descontar letras al público cur yo origen importe inversiones permanentes en bienes raíces o muebles, salvo que el Directorio lo autorice excepcionalmente y por razones fundadas (Artículo 39; letra e), in* ciso final).

e) Descontar letras al público, cuyas operaciones tengan un origen en el servicio de obligaciones, en fines de consumo o en el financiamiento de negocios especulativos; (Artículo 39 , letra e), inciso final).

f) Descontar docuentos al Fisco, cuyo monto o montos excedan un duodécimo del Presupuesto Anual de la Nación, o excedan el $66 \%$ de ese duodécimo en un semestre (Artículo 39 , letra a) inciso final).

Inhabilidad de los directores para intervenir en determinadas operaciones de crédito

\section{Generalidades}

Para concluir el capítulo de las operaciones crediticias del Banco
Centrál señalaremós lás dîspósicio nés de la Ley Orgánica que impidèn a sús Directores intervenir en determinadas operaciones de créditos, como también, las sanciones a que quedan 'afectos en casos de trasgresión a estas normas.

\section{Fuente legal}

El artículo 31 del D.F.L. 247 de 1960 establece que "ningún Director podrá intervenir ni votar en operaciones de crédito, inversiones u otros negocios que interesen a él o a empresas particulares con quienes mantengan vínculos de participàción, dependencia o ingerencia en si administración ; igual prohibición regirá con respecto a los negocios u operaciones que interesen a sus $\mathrm{pa}^{-}$ rientes hasta el tercer grado de consanguinidad y segundo de afinidad inclusives".

"No se entenderán comprendidos en estas prohibiciones, los acuerdós destinados a producir éfectos de ta răcter general".

\section{Enunciado}

De lo expresado en el artículo 31 transcrito se desprende que tos $\mathrm{Dr}^{-}$ rectores del Banco Central no po drán intervenir en las siguientes operaciones de crédito de aćuerdó a las situaciones que se señalèn:

a) Operaciones crediticias de cual, quier naturaleza que interesen a los mismos Directores;

b) Operaciones crediticias que interesen directamente a empresas particulares en las cuales los Direc: tores mantienen vínculos de participación, dependencia o tienen ingerencia en su administración; y

c) Cuando interesen a sus parien- 
tes hasta el tercer grado de consanguinidad y segundo de afinidad inclusives.

Sin embargo pueden intervenir y votar en las operaciones. aun cuando se presenten algunos de los casos señalados, si los acuerdos aprobados aprobados están destinados a producir efectos de carácter general.

\section{Sanciones}

La sanción para el caso de contravención al artículo 31 se encuentra en el artículo siguiente que dice: "Los Directores o empleados del Banco Central de Chile, que a sabiendas ejecuten operaciones prohibidas por Ley, responderán personalmente con sus bienes de las pérdidas que dichas operaciones irroguen al Banco, sin perjuicio de las sanciones legales que correspondan".

De la disposición transcrita parece desprenderse que la sanción se aplicaría sólo cuando las operaciones prohibidas irroguen pérdidas al Banco. Pero esto no quiere decir que la infracción de los Directores que no irrogue pérdidas al Banco quedaría sin sanción, ya que la Ley de Bancos en sus artículos 20 y 21 contiene normas generales de sanción y que se aplican a los casos señalados en el artículo 31 del D.F.L. 247 de 1960.

Los artículos mencionados del D.F.L. 252 de 1960, Ley General de Bancos, establecen:

"Las instituciones sometidas a la fiscalización de la Superintendencia que incurrieren en alguna infracción a esta ley, a sus leyes orgánicas. a sus estatutos o a las órdenes legalmente impartidas por el Superintendente, que no tenga señalada una sanción especial podrán ser amonestadas, censuradas o penadas con multa de cincuenta o diez mil escuclos". (Artículo 20).

"Los Directores o empleados de una empresa bancaria que, a sabiendas, aprueben o ejecuten operaciones no autorizadas por la Ley, por los Estatutos o por las normas impartidas por la Superintendencia, responderán con sus bienes de las pérdidas que dichas operaciones irroguen a la empresa". (Artículo 21).

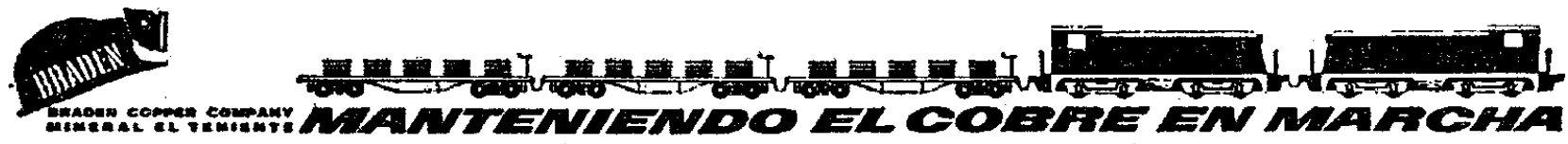

